\title{
The use of selected English determiners by Polish users of English at different proficiency levels
}

\author{
Artur ŚWIĄTEK \\ Uniwersytet Pedagogiczny w Krakowie/ Pedagogical University of Cracow \\ E-mail: artur.swiatek@up.krakow.pl,
}

\begin{abstract}
The objective of the article is a theoretical and practical analysis of the use of selected English determiners (e.g. articles, quantifiers, etc.) by Polish users of English representing different proficiency levels (B2-C2, in accordance with the CEFR, which stands for the Common European Framework of Reference for Languages). The practical part of the article will be centred on the demonstration of the use of the selected determiners based on the available corpus of L2 users (PELCRA - PLEC). The first acronym denotes Polish and English Language and Corpora for Research and Applications (PELCRA), which is the result of scientific work of scholars from the University of Łódź. The other one (PLEC), stands for PELCRA English Learner Corpus (see the "References" section below). It is commonly known that learners/students find it difficult to use English determiners properly, as they are differently realised in their native language. It is generally assumed that learners/students will demonstrate different strategies in the use of the determiners in question. The strategies selected by them will revolve around hesitations, overuse, avoidance, non-use of the definite article the or the word that. Hence such idea of the research occurred, the objective of which is to verify and demonstrate learners'/students' performance with reference to the selected words, which are challenging in all contexts.
\end{abstract}

Keywords: English determiners, articles, L2 users, PLEC

\section{Introduction}

In accordance with what Th. Klammer, M.R. Schulz and A.D. Volpe (2009) state, function words are words that have little lexical meaning or have ambiguous meaning, as they signal the structural relationships that words have to one another and simultaneously are the glue that holds sentences together. In addition they serve as important elements to the structure of sentences. They comprise, e.g. auxiliary verbs, pronouns, conjunctions and determiners. It is believed that when fluency breaks down in spontaneous speech, speakers tend to repeat pronouns and conjunctions (H.H. Clark/ E. Clark 1977).

Pronouns and conjunctions are types of function words that have a grammatical, or functional, role but do not carry a full lexical meaning (R.R.K. Hartmann/ F.C. Stork 1972, R. Quirk et al. 1985)

Commencing our elaboration on the selected determiners, it is advisable to direct our attention to the role determiners fulfill in any language. D. Biber, S. Conrad and G. Leech (2003: 26) state that "determiners normally precede nouns and they are used to help clarify the meaning of the noun". The most significant determiners in English 
are the following:

- the definite article the, indicating that the referent (whatever is referred to) is assumed to be known by the speaker and the person being spoken to (or addressee);

- the indefinite article $a$ or an, making it clear that the referent is one member of a class (e.g. a car);

- demonstrative determiners, which indicate that the referents are 'near to' or 'away from' the speaker's immediate context (e.g. this man, that man, etc.);

- possessive determiners, which tell us who or what the noun belongs to (e.g. my car, your school, her baby, etc.);

- quantifiers - specify how many or how much of the noun there is (e.g. every corner, some children, etc.).

\section{The function of that based on available online dictionaries}

Prior to commencing our discussion on the assumed research problems, it would be advisable to outline how the function of the first analysed word, namely that, is presented by available online dictionaries. For this reason, three most popular and relevant monolingual English-English dictionaries were selected. They were: Merriam Webster, The Free Dictionary and Longman Dictionary of Contemporary English Online. These sources are significant as they depict and comprehensively describe the syntactic roles the analysed word that fulfils in miscellaneous contexts. What is also vital is that L2 students very frequently select such online sources to verify their knowledge. Apparently, L2 students, representing lower proficiency groups, e.g. A1-B1, do not use monolingual dictionaries online, as they tend to select a great deal of bilingual, Polish-English dictionaries, as it is easier for them to comprehend any meaning of the searched word when they need to check it up in such dictionaries. They select the most popular dictionary for their needs, namely Diki. However, due to lots of deficient contexts and imperfections this dictionary provides, we will not rely on it and shall not demonstrate the use of that based on this bilingual dictionary.

Starting our demonstration with presenting what the first online dictionary offers us, we will focus on Merriam Webster Dictionary, which juxtaposes the roles that fulfills, which are as follows:

1. That is a pronoun, because:

- it depicts "the person, thing, or idea indicated, mentioned or understood from the situation", as in: "that is my father";

- it refers to "the time, action or event specified", as in: "after that I went to bed";

- it relates to "the kind or thing specified as follows: the purest water is that produced by distillation";

- it may be "one or a group of the indicated kind", as in: "that's a cat - quick and agile".

2. That is used as a function word:

- "after and to indicate emphatic repetition of the idea expressed by 
a previous word or phrase, e.g. he was helpful, and that to an unusual degree";

- "immediately before or after a word group consisting of a verbal auxiliary or a form of the verb be preceded by there or a personal pronoun subject to indicate emphatic repetition of the idea expressed by a previous verb or predicate noun or predicative adjective, e.g. Is she capable? She is that".

3. That is used as a conjunction:

- "to introduce a noun clause that is usually the subject or object of a verb or a predicate nominative, e.g. said that he was afraid";

- "to introduce a subordinate clause that is anticipated by the expletive it occurring as subject of the verb, e.g. it is unlikely that he'll be in";

- "to introduce a subordinate clause that is joined as complement to a noun or adjective, e.g. we are certain that this is true; the fact that you are here";

- "to introduce a subordinate clause modifying an adverb or adverbial expression, e.g. will go anywhere that he is invited";

- "to introduce an exclamatory clause expressing a strong emotion, especially of surprise, sorrow or indignation, e.g. that it should come to this!"

The second online dictionary source we may entirely rely on in our subsequent corpus analysis is The Free Dictionary. It reflects the way the word that is used on the basis of the contexts below.

1. That is a pronoun because it is used:

- "to refer to the one designated, implied, mentioned or understood, e.g. what kind of soup is that?";

- "to refer to the event, action or time just mentioned, e.g. after that, he became a recluse";

- "to indicate the further or less immediate one: that is for sale, this is not";

- "to emphasise the idea of a previously expressed word or phrase, e.g. he was fed up, and that to a great degree";

- it depicts "the one, kind, or thing; something, e.g. "she followed the calling of that which she loved";

- "as a relative pronoun to introduce a relative clause, especially a restrictive clause, e.g. the car that has a flat tyre".

2. That is a conjunction because it is used:

- "to introduce a noun clause that is usually the subject or object of a verb or a predicate nominative, e.g. "'that contemporary American English is exuberantly vigorous is undeniable"";

- "to introduce a subordinate clause stating a result, wish, purpose, reason or cause, e.g. 'she hoped that he would arrive on time'; 'he was saddened that she felt so little for him'".

- "to introduce an anticipated subordinate clause following the expletive it occurring as subject of the verb, e.g. "it is true that dental work is expensive",;

- "to introduce a subordinate clause modifying an adverb or adverbial expression, e.g. "will go anywhere that they are welcome""; 
- "to introduce a subordinate clause that is joined to an adjective or noun as a complement: 'was sure that she was right'; 'persists in the belief that rates will rise soon"”.

The final dictionary online that we may quote and refer to here is Longman Dictionary of Contemporary English Online. It juxtaposes such roles the word that fulfils in the listed contexts:

1. That is a pronoun because:

- it is "used to refer to a person, thing, idea, etc. that has already been mentioned or is already known about", e.g.:

a) "You never cared about me."

b) "That's not true."

c) "I wish you wouldn't say things like that?"

d) "Victoria Street?" "That's where my sister lives."

e) "He killed a man once and that's why he had to leave Ireland."

f) "We've been cheated, she said". "I have to go, she said, and with that she hung up the phone."

2. That is a conjunction because it is used:

- "after verbs, nouns and adjectives to introduce a clause which shows what someone says or thinks, or states a fact or reason", e.g.:

g) "If she said that she'd come, she'll come."

h) "I can't believe that he's only 17."

i) "Are you sure that they live in Park Lane?"

j) "The fact that he is your brother-in-law should not affect your decision."

k) "He might have left the money for the simple reason that he didn't know it was there."

Having demonstrated the list of the selected roles the word that fulfils in miscellaneous contexts provided by the three most relevant monolingual online dictionaries, let us now proceed to the demonstration of the roles fulfilled by the second word we intend to describe and analyse in this paper, that is the definite article the.

\section{The function of the based on current literature}

Due to the scarcity of space devoted to this article, enormity of the uses and functions of the definite article the as well as the abundance of research in this respect, we shall be able just to outline the most relevant and frequent uses of this determiner. For the same reasons as listed above, we were forced to resign from juxtaposing the contexts provided by the available online dictionaries.

M. Parrot (2007: 47) states that we use the to signal to our reader or listener that we know or will soon know what we are referring to. It motivates the reader or listener to search for the most obvious area of common ground in order to find such identification. The context is usually the most important factor in assisting us to complete our search successfully.

Hence, we use the definite article to refer backwards or forwards in a text or conversation. In addition, we refer to our shared experience or general knowledge. In 
the examples listed below, the definite article the signals that we are aware which children are meant. We use the context to help us to identify who they are:

- referring backwards, e.g. "when I was out I passed a young couple with two little girls and a boy"; "I thought I knew the parents but I didn't recognize the children at all" (i.e. "the two little girls and the boy");

- referring forwards, e.g. "take prizes for the children who win" (i.e. "those children who will win");

- external reference, e.g. "shouldn't we pick up the children soon?" (i.e. "our children"- shared knowledge), "Herod killed the children" (i.e. "the Israelite children in the Bible story" - general knowledge).

Another very important factor analysed by M. Parrott (2007: 355) is the use of the with reference to information that relative clauses qualify and L2 users generally are obliged to learn that this is necessary. In the presented example below, the definite article the alerts us to expect a relative clause identifying which person the speaker is talking about: Do you know the person who just left the room? Therefore, we are obliged to use the to signal that the clause that follows is going to specify which thing or person we are referring to.

Following M. Hewings (1999: 116), we use the to find out which person or thing we mean, as listed in the following examples below:

- What do you think of the table? (Apparently, the table we are looking at.)

- This tastes lovely. What's in the sauce? (We assume the sauce here on our plate.)

- The tree looks beautiful now that it's spring. (We tend to be familiar with the tree, e.g. the one here in our garden.)

M. Hewings (1999: 116) mentions further that we should notice the peculiar use of the in fictional writing (e.g. novels, short stories, etc.), where we often mention something for the first time and use the to build up suspense, expectation, etc. as quoted in this introductory part to a story below:

- The woman opened the gate and looked thoughtfully at the house.

\section{The assumed research problems}

The predominant research problem investigated in the paper is the extent to which Polish users of English are able to comprehend the polysemous system of the selected English determiners. They, depending on the available context, may have some meaning or just signal it, e.g. the English word 'that' may be a pronoun, as in, e.g., I like that or a demonstrative determiner, as in, e.g., That problem is unthinkable.

The subsequent, equally significant research problem, assumed by the author of the article, is the overuse of the definite article the, as well as its omission in the contexts where it is absolutely mandatory.

Non-native users of English (our respondents) can use English determiners. However, they tend to have problems with distinguishing between demonstrative determiners and demonstrative pronouns, e.g. "This idea is good" vs. "This is a good idea".

When a word possesses its grammatical function, the students' doubts and 
hesitations tend to occur and there are problems with expressing a grammatically appropriate spoken register.

\section{The study}

The quantitative study will be centred on the Corpus analysis (the afore-mentioned PLEC) with reference to different proficiency levels, comprising the levels ranging from B2 to $\mathrm{C} 2$ (based on the Common European Framework of Reference for Languages). The proficiency levels from A1 to B1 were excluded from the study, as the number of imperfections, hedging expressions, errors and hesitations in the students' performance was too high.

We will focus on the instances of the afore-mentioned selected words comprising a group of function words used in the available spoken register. This register was the only one we could rely on in this study. The age variable ranged from 18 to 28 years old. There were $90 \%$ of women and $10 \%$ of men registered in the available corpus material.

Spoken utterances of non-native (Polish) users of English were registered during English conversations classes both in high schools and in English philology departments. 86000 contexts have been analysed for that and 32000 contexts for the. The contexts comprised spoken register only.

\section{Corpus analysis 1}

The corpus analysis demonstrated below is divided into sections devoted to that and the correspondingly. Each section presents and illustrates the use of the investigated words. The bracketed information in each of the selected instance of use below contains the mode it was constructed in, followed by the age of the respondents, the proficiency level, gender and education level, e.g. high school or university students.

The illustration of the spoken mode is presented as accurately as it was performed by the speakers, hence some parts of the spoken register may strikingly indicate the imperfection of the communication act, which is frequently due to the lower proficiency level (e.g. B2) or it may be the reason for a high level of impediment, e.g. stress indicated by the occurrence of hesitations, hedging expressions, which are almost non-observable in fluent speech of native speakers.

\section{(1) That as a conjunction}

The corpus analysis of the use of that as a conjunction is illustrated below. For the sake of clarity, the analysis is conducted in accordance with the proficiency level and the most frequent contexts that we could observe basing on the available corpus material. They are as follows:

1. "oh, the best I like this fact that, er, I can, mmm..." (spoken, B1, age:19, sex: f, level:1_yr_BA);

2. "yeah I think that I can actually learn a lot about er our world er because er living here in one place mmm" (spoken, age:19 sex: f, level:1_yr_BA); 
3. "and I think that symbolises er well obviously the studies and the wires are erm symbol of er..." (spoken B1, age: 19, sex: m, level: 1_yr_BA);

4. "that the students' life is so colourful so full of life so full of activities that it's..." (spoken, B1, age: 19, sex: m, level: 1_yr_BA);

5. "thanks to the erm things that they did in this time" (spoken, B1, age: 19, sex: m, level: 1_yr_BA);

6. "so it's not so er boring environment I think that colours are important in our lives" (spoken, C1, age: 19, sex: f, level: 1_yr_BA);

7. "imagine that these photographs were submitted for a competition" (spoken, C1, age:23, sex: m, level:2_yr_MA);

8. "really er but they realized that probably this is something I can develop and because I have very low voice and this low voices can be mmm" (spoken, C1, age: 23, sex: m, level:2_yr_MA);

9. "I know it is that if you try to speak in their language they are much nicer because you try to communicate with them" (spoken, C2, age:22, sex: f, level: $1 \_\mathrm{yr}$ _MA);

10. "is $\mathrm{mmm}$ like pro that you are breathing with a fresh air so it's more healthier" (spoken, C2, age: 18, sex: f, level: secondary school).

(2) That as a pronoun

The corpus analysis of the use of that as a pronoun is illustrated below. For the sake of clarity, the analysis is conducted in accordance with the proficiency level and the most frequent contexts that we could observe basing on the available corpus material. They are as follows:

1. "that's the whole magic of it I just er... ." (spoken, B1, age: 19, sex: f, level: $1 \_\mathrm{yr}$ MA);

2. "I'm sorry about that" (spoken, C1, age:23, sex: m, level:2_yr_MA),

3. "No, don't worry about that" (spoken, C1, age:23, sex: m, level:2_yr_MA);

4. "yyy because I use yyy I use products which are not some common as in different yyy for example restaurants something like that" (spoken, C1, age:22, sex: f, level:1_yr_MA);

5. "mmm, that's interesting. Any other examples?" (spoken, C1, age:22, sex: m, level:1_yr_MA);

6. "that was something something like a challenge to be to be met and I decided that it would be just..." (spoken, C1, age:23, sex: m, level: 2 yr_MA);

7. "are you interested in developmental psychology, is that correct? Or some aspects of developmental psychology?" (spoken, C2, age: 23, sex: m, level: 2_yr_MA);

8. “er can you tell me something more about that?" (spoken, C2, age: 23, sex: m, level: $\left.2 \_y r \_M A\right) ;$

9. "yyy how often do you eat out? and do you eat out on er any special occasions? er occasions or just like that?" (spoken, age:23, sex: m, level:2_yr_MA);

10. "DNA or er something like that yes" (spoken, C2, age: 18 , sex: f, secondary school). 


\section{Corpus analysis 2}

The corpus analysis of the use of the is illustrated below. For the sake of clarity, the analysis is conducted in accordance with the proficiency level and the most frequent contexts that we could observe basing on the available corpus material. The parts in bold as well as the underlined ones indicate the observable discrepancy between the research assumptions of the author of the article and, very frequently, the erroneous use of the definite article in the presented contexts. They are as follows:

(1) The

1. "oh, the best I like this fact that, er, I can, mmm... " (spoken, B1, age:19 sex: f, level: $1 \_$yr_BA);

2. "er, it's not only the learning that is important but er also the private life" (spoken, B1, age:19, sex: m, level:1_yr_BA);

3. "light-minded if I may say so but er I think that's a the whole magic is that..." (spoken, B1, age:19, sex: m, level:1_yr_BA);

4. "how the what what questions are because the point is to have people unprepared OK?" (spoken, C1, age:23, sex: m, level:2_yr_MA);

5. "when I when I yyy when I yyy watch Magda Gessler Magda Gessler 's programme I think that it is rather programme about the about this lady not about the cooking or restaurants" (spoken, C1, age:22, sex: f, level:1_yr_MA);

6. "but sometimes I sometimes I read them just to know what people think to compare the my opinion and their opinion" (spoken, $\mathrm{C} 1$, age:23, sex: $\mathrm{f}$, level:2_yr_MA);

7. "it 's going quite well so I think we'll we will have good infrastructure before the Euro 2012" (spoken, C2, age:22, sex: m, level:1_yr_MA);

8. "I think er we should maintain our some of our erm values but it 's yyy it 's hard to predict if the Europe will be a federation" (spoken, C2, age:22, sex: m, level:1_yr_MA);

9. "it 's from the bigger brother of fiat cinquecento so punto and it 's slightly modified so" (spoken, C2, age:23, sex: m, level:2_yr_MA);

10. "it can be pretty close to the this city, for example, it can be just at the edge of the city" (spoken, C2, age: 19, sex: m, level:1_yr_MA).

\section{Conclusions}

As for the conclusions regarding the use of that, very significant differences were observed in the frequency of the use of the selected word depending on the proficiency level (B1-B2). It was very challenging to observe (and hence very problematic to demonstrate in the corpus material above) the use of that as a demonstrative determiner, as in, e.g., that way, even at the highest proficiency levels in the use of a foreign language $(\mathrm{C} 1, \mathrm{C} 2)$.

As far as the use of the definite article the is concerned, we were able to observe hesitations, overuse, omission, discrepancies and indecisiveness across all mentioned proficiency levels.

The study had its limitations, which were: a low number of variables (age and 
gender); only two investigated words, namely that and the; only one available corpus at our disposal, which enabled us to very basically verify the use of the words in question. The availability of register in the corpus was constrained as well. We had access only to the spoken register, which also shed a rather limited light on this very complex and intriguing issue of the use of function words by L2 users in general.

In the future, we intend to conduct a more in-depth study not only of qualitative, but also of quantitative character. It would be advisable to calculate the research results more accurately, via percentage calculation, which would allow us to observe this phenomenon more extensively.

In addition, an increase in the number of variables is worth considering. The provision of the specific division into spoken and written registers is advisable to allow a more precise observation of the use of function words in spontaneous speech and in the written-ready made registers.

Finally, it would be very practical to verify the obtained research results based on the available corpus with other available corpora (e.g. ICLE). Such verification would shed positive light on the use of function words among other non-native users of English.

\section{Pedagogical implications}

The research results from further study will certainly allow us to obtain a clearer insight into the complicated role, which is fulfilled by the selected function words in a foreign language.

It is believed that the obtained research results will allow us to comprehend their syntactic changeability and their signalled meaning during classes with both language school learners as well as with English philology students to increase their overall awareness related to such linguistic phenomena. Such incorporation and the students' subsequent awareness of such phenomena will definitely positively influence their linguistic fluency.

\section{References}

Biber, D./ S. Conrad/ G. Leech (2003), Student Grammar of Spoken and Written English. Hampshire.

Clark, H.H./ E. Clark (1977), Psychology and Language. An Introduction to Psycholinguistics. New York.

Hartmann, R.R.K./ F.C. Stork (1972), Dictionary of Language and Linguistics. London.

Hewings, M. (1999), Advanced Grammar in Use. A Self-study Reference and Practice Book for Advanced Learners of English. Cambridge.

Klammer, Th./ M.R. Schulz/ A.D. Volpe (2009), Analyzing English Grammar (6th ed). New York.

Levelt, W.J.M. (1992), Accessing Words in Speech Production: Stages, Processes, and Representations. In: "Cognition" 42, 1-22. 
Parrott, M. (2007), Grammar for English Language Teachers. Cambridge.

Pęzik, P. (2012), Towards the PELCRA Learner English Corpus. In: P. Pęzik (ed.), Corpus Data across Languages and Disciplines. Łódź, 33-42.

Quirk, R./ S. Greenbaum/ G. Leech/ J. Svartvik (1985), A Comprehensive Grammar of the English Language. London.

\section{Online sources}

(URL https://www.ldoceonline.com/). [Accessed on: 07.05.2018].

(URL https://www.merriam-webster.com/). [Accessed on: 07.05.2018].

(URL http://pelcra.pl/plec/). [Accessed on: 10.05.2018].

(URL http://www.thefreedictionary.com/). [Accessed on: 17.05.2018]. 